\title{
Contraceptive Utilization Among Couples and Associated Factors in Dodota District, Oromia Region, Ethiopia
}

\author{
Kedir Gatiso Jagiso ${ }^{1}$, Legesse Tadesse Wodajo*2 and Seid Yusu ${ }^{2}$ \\ ${ }^{1}$ Dodota District Health Office, Arsi Zone, Oromia Region, Ethiopia \\ ${ }^{2}$ Department of public health, College of Health Sciences Arsi University, Ethiopia
}

Received: April 10, 2018; Published: April 20, 2018

*Corresponding author: Legesse Tadesse Wodajo, Department of public health, College of Health Sciences Arsi University, Ethiopia, Tel: 251911367083; Email: legesset2008@gmail.com

\begin{abstract}
Introduction: Family planning service technology has the potential to benefit to people at lower cost than any other technology now available for development. In the study area there is no adequate information that this study intended to fill up.

Objective:This study assessed contraceptive utilization among couples and associated factors in Dodota District, Oromia, Region, Ethiopia.

Study Period and Design: A cross sectional, community-based study was conducted in four rural and one urban Administrative village of Dodota District of south east Ethiopia; between September 01, 2015 and April 30, 2016. Systematic random sampling used to select the study subjects. A pre-tested questionnaire in local language was used to collect information from the couples. Similar questions were posed to the couples simultaneously but at distance they couldn't hear each other.
\end{abstract}

Result and Discussion: A total of 345 married couples studied. Age of the husband, age of women, husbands having family planning information, number of children ever born by women, women education and family size were statistically independent predictors of family planning use by women.

Conclusion and Recommendation: In married couples, both women and men factors affect family planning service utilization by the women. Therefore, allprogramstargeted topromotingfamilyplanninghavetoaddressbothmenandwomen,menshouldbeconsideredasanimportantagentto expand family planning utilization.

Keywords: Couples Fertility; Family Planning; Contraceptive Utilization

\section{Introduction}

\section{Background}

Worldwide population growth rate has declined from its historic peak of $2.1 \%$ per year in the late 1960 's to $1.13 \%$ today. However, Sub-Saharan Africa still faces the highest fertility and population growth rate at $4.71 \%$ in the world. Ethiopia is one of those countries having high natural rate of population increase, with an estimated at $2.6 \%$ [1].Ethiopia had an estimated population of approximately 85 million at the end of 2007. Eighty-five percent live in rural areas and only half of the population has access to health care services. Immunization and antenatal care coverage are very low, $55.7 \%$, and (58.3\% ANC-1 \& 32.1 ANC-4) respectively [2]. The country has high total fertility rate (4.1 children per women), and a high maternal and infant mortality rate (353 per 100,000 live birth and 58 per 1000 live births respectively).The gross school enrolment ratio is $88 \%$ for primary school and $22 \%$ for secondary school.
The nation has a very low annual per capita income i.e. 8.4 in average. $7.8 \%$ of the population are at poverty line and $30 \%$ of the population are below poverty line, world bank 2011 [3].Population growth in Ethiopia is not in parallel with the development of health services and other basic infrastructures. To cope with this alarming population growth and improve maternal and infant survival, there need to be a comparable increment in health care coverage and other infrastructures. Considering the low socioeconomic status of the country, resources are insufficient to expand infrastructures needed for the growing population. Hence, the alternative is regulation of fertility to the extent that the family, community and country can afford. Family planning service technology has the potential to benefit to people at lower cost than any other technology now available for development [4].

Family planning services in Ethiopia was started in 1966 by Family Guidance Association of Ethiopia, a non-governmental 
organization. In 1975, the Ethiopian government started integrating family planning with maternal and child health services. After the adoption of the population policy in 1993, a number of other stakeholders have been involved in family planning promotion [5]. Despite the efforts to implement family planning by the Ethiopian government and other stake holders, the results obtained and the goal desired remain unachieved. As reported by the center for national health development, contraceptive acceptance rate is low (42\%) [6]. other evidences include high population growth rate; persistent high total fertility rate, 5.9 in 2000, 4.8 in 2011 and 4.1 in 2014; very low contraceptive usage (29\%) [7], and high rates of unwanted pregnancy and its complications. According to the guidelines for family planning services, family planning is a means of promoting the health of women and families. Accordingly, all individual's male or female who can conceive or cause conception regardless of age or marital status are eligible for family planning services [8].

The family planning services rendered are primarily restricted to maternal and child health centers, where only women are invited for the service. In addition, most research on fertility and family planning issues in developing countries involved only women. The roles of the male in making family life decisions including the reproductive health life of his wife are not given emphasis [9]. Some of the reasons forthenewinterestinmaleinvolvementinfamilyplanning(FP) services are: men are more favorable to the general principle of family planning than will be assumed. Male support affects both the adoption and the correct use of female contraceptive utilization. The body of knowledge regarding male involvement programs is growing and improving, and family planning agencies are finding that male involvement programs can be cost effective if they are highly focused and offer male contraceptive methods directly or by referral.

The international consensus reached at International Conference on Population Development has created a momentum for action that means male involvement in FP utilization. Recently most countries, including Ethiopia, are trying to adapt the new initiative of involving men in family planning programs[10].Despite this initiative the fact on which men characteristics combined to women factors would be influential in modifying family planning use are not well known. Therefore, the roles of males along with women factors that influence the utilization of family planning methods by couples need to be studied in the socio-cultural contexts in order to develop appropriate interventions to achieve the desired outcome of family planning program.

\section{Methods}

\section{Study area}

Dodota District is found in Arsi zone, Oromia regional state, Ethiopia. It is one of the 25 districts in Arsi zone. Dodota district is further divided in to 15 Administrative villages, three urban and twelve rural. The district's total population was 82,412 according to the 2007 Census year. The projected population for 2008 is 84,729 considering the $2.6 \%$ annual population growth rate of the country. Sixty eight percent of the population is living in rural areas. The
Oromo are the major ethnic group. The study was conducted from September 01, 2015 to April 30, 2016 in twelve rural and three urban Administrative villages of Dodota District, in Arsi zone, Oromia regional state, Ethiopia.

\section{Study Design and Period}

A community based cross-sectional study was carried out from September 01, 2015 to April 30, 2016.

\section{Source Population}

All married couples residing within Dodota District.

\section{Study population}

There were 15 Administrative villages within Dodota District. The sample population for the study was drawn from all married couples residing in five randomly selected Administrative villages (four rural and one urban).

\section{Inclusion criteria}

a. Men with wife in fertile age group [that is the wife age should be between 15-49 years]

b. In case of polygamy, man with his latest wife was included; this is in assumption that the husband is going to had had more children with the new wife.

c. Permanent residents of the area (lived at the area at least for one year, as during the daily period laborers may came to the area and settle for short period and may not share similar behavior with local people).

\section{Exclusion criteria}

Married women whose age is not in fertile period and women with health problem (critically ill and unable to communicate).

\section{Sample size and sampling procedures:Sample size determination}

Sample size was calculated using the formula for a single population proportion with the following assumptions: Both husband and wife as a single study subject. Proportion of both wife and husband approving family planning use to be $29 \%$, as reported by wives during Ethiopian Demographic and Health Survey 2011[7], $0.95 \%$ confidence level, $(\alpha=0.05)$ the degree of precision was $5 \%$ and $10 \%$ non-response rate.Using the above assumptions, the total required sample was calculated as.n $=(Z \alpha / 2) 2 * \mathrm{p}(1-\mathrm{p}) /$ $\mathrm{d} 2=(1.96) 2 * 0.29(0.71) /(0.05) 2=316$, Where: $\mathrm{P}=$ estimated proportion of married women who used modern family planning (29\%), d=margin of error (5\%), $\mathrm{Z} \alpha / 2=$ critical value at $95 \%$ confidence level (1.96).The calculated sample size in couples was 316 and 10 percent none-response added to give us the total sample in couple of 348. Since a couple is two in person, the calculated sample was multiplied by two and became 696 subjects.

\section{Sampling Procedure}

There were 15 administrative villages in Dodota District. Out of these 12 rural and 3 urban Administrative villages in the District were eligible for the study.From those 12 rural and 3 
urban Administrative villages 5 was selected randomly by lottery method. In each Administrative village households were allocated proportional to their population. This proportional allocation to each Administrative village was by assumption that not all of them have equal number of households.The study unit was house hold with the assumption that each house would have married couples. The housing unit was selected by systematic random sampling that is by dividing the total number of households in each selected Administrative village.Since there was already existing sampling frame at health post from community health management information system (CHMIS) folder therefore no need of preparing new sampling frame.

Systematic selections of the households were done as follows. The border at entrance of the Administrative village by the highway from Dera Town to Addis Ababa was used as starting point for the random selection of the housing units. The number of intervals from one housing unit to another housing unit was already identified by dividing the total number of households in the Administrative village to the allocated sample size. Using the guide man, from the border identified the nearby houses relatively straight to each other are counted until the number of housing unit in one interval was attended. Out of the frame counts within the interval, the first household was selected by lottery method. That identified household was used as the first household for the study. The subsequent households were identified by the interval calculating for each Administrative village. Study subjects were married couples living in the house.

\section{Variables of the Study}

Dependent variables: Family planning service utilization

Independent variables: Socio demographic and cultural determinants Age, sex, religion, educational status, Age at first marriage, age at first born, type of marriage, anticipated means of old age support, number of children (ever born, number of children alive, ideal children wanted)

\section{Operational Definitions:}

a. Couple: Male and female who are in marital relationship.

b. Administrative village: Is the smallest administrative unit under governmental administrative structure.

c. District: Is governmental administrative unit that includes different number of Administrative village.

d. Ever use of contraception: those respondents who were using contraception once in their life. It includes those who are using contraceptive methods during the data collection period.

e. Current use of contraception: those respondents who are using contraceptive method during the period of data collection.

f. No formal education: are those respondents who have never went to school and also cannot read and write.

\section{Data Collection Procedures}

An identification number which included the Administrative village code and serial number was given for each participating household. For each Administrative village, the serial number was from 01 to 90. And the Administrative village coded from " $\mathrm{A}$ " to " $\mathrm{E}$ ". For example, the first selected house hold in Administrative village "A" was identified by "A01" and the next selected household from same Administrative village would get "A02" and the rest were identified in a similar way. Filled formats of the husband should have the same identification number with that of his wife, which included the Administrative village code, and the serial number given for the household.Data collectors identified the study households using sampling frame taken from Health Post. Although the respondents name was not written on the questionnaire, on already prepared format, the data collectors documented the name of the head of households corresponding to the serial number. This was helpful during the rechecking and refilling of the questionnaire in case of omissions or inconsistency found.

\section{Data quality assurance}

Training of data collectors and supervisorsTen high school graduates ( 5 males and 5 females) and 3 diploma graduate nurses were recruited and trained for three days to serve as data collectors and supervisors respectively. The training consisted of the objectives of the study, introduction of questionnaire format, procedure of interviewing couples and method of reporting to immediate supervisor. The role and communication of supervisors to data collectors and coordinators were thoroughly explained.A pretest was carried out using prepared format in the community not selected for the study. During the field practice, each data collectors were made to fill two questionnaires with their supervisor close to them. Discussion took place the following day concerning the filled questionnaires, interview procedures and communication between data collectors, and supervisors. More clarification was made to data collectors on the items they didn't understand during their field practice.The quality of data was controlled at different levels for completeness and consistency; first by data collectors and supervisors every day, then by the investigator, and finally during data entry. On the third day of data collection, the investigator and supervisors revisited 10 of the visited couples, two from each Administrative village and witnessed that the interview are undertaken as planned. The investigator undertook computer data entry, cleaning and edition. The inconsistent and missed questionnaires were excluded from analysis. These two sets of data were compared, and some of the questionnaires were rechecked and inconsistencies corrected.

\section{Data Collection}

Trained data collectors were collected data on the variables from couples over 6 days. When the couples couldn't have found during house visits, the data collectors choose the next household in either side of the visited one.The data collectors were paired in such a way that a pair consists of a male and a female. During the process of data collection, the male data collector interviews 
the husband while the female data collectors interviewed the wife at the same time, but at a distance that the couples were not hear each other. This was to avoid the probable influence of one partner on the other partner on the information to be gathered. It hoped that female data collectors could best able to solicit open and honest replies from the female respondents on sensitive issues.A supervisor was responsible for 2 pairs of data collectors and collected filled questionnaires every day and checked for inconsistencies and omissions. Submission of filled formats to coordinator was made every day, which was rechecked for any inaccuracy. Formats with problem were sent back to supervisors for re interview. Then SPSS version 21.0 was used, for data entry, compilation and analysis. Ethical considerationsEthical clearance was obtained from Research Ethical Committee of College of Health Science, Arsi University. And written consent was obtained from Arsi zone and Dodota District Health Office. All the study participants were informed about the purpose of the study and their consent was obtained before interviews and the information given by each respondent remain confidential.

\section{Result}

Socio demographic characteristic of couples participate in study at Arsi Zone Dodota District, South East Ethiopia, 2016.0f those 348 couples invited for the study, information gathered from 345 couples were included in the analysis, 345 married men and 345 married women, making a total study population of 690.Three of the couples couldn't be found after repeated visit. The numbers of those excluded from the analysis was less than the expected nonresponse rate. Mean age in years was 36.54 for men while 28.50 for women and the mean age difference were 8.04.(Table 1).

Table 1: Socio Demographic Characteristic of Couples Participate in Study Resided at Five Administrative Village of Arsi Zone Dodota District, South East Ethiopia 2016.

\begin{tabular}{|c|c|c|c|c|c|}
\hline \multirow{2}{*}{$\begin{array}{c}\text { Back ground } \\
\text { Characteristic }\end{array}$} & & \multicolumn{2}{|c|}{ Women } & \multicolumn{2}{|c|}{ Men } \\
\hline & & No & $\%$ & No & $\%$ \\
\hline \multirow[t]{7}{*}{ Age } & $15-19$ & 12 & 3.5 & 22 & 6.4 \\
\hline & $20-24$ & 45 & 13 & 48 & 13.9 \\
\hline & $25-29$ & 97 & 28.1 & 76 & 22 \\
\hline & $30-34$ & 81 & 23.5 & 65 & 18.8 \\
\hline & $35-39$ & 76 & 22 & 84 & 24.3 \\
\hline & $40+$ & 34 & 9.8 & 50 & 14.5 \\
\hline & Total & 345 & 100 & 345 & 100 \\
\hline \multirow[t]{5}{*}{ Ethnicity } & Oromo & 323 & 93.6 & 321 & 93 \\
\hline & Amhara & 17 & 4.9 & 19 & 5.5 \\
\hline & Tigre & 0 & 0 & 1 & 0.3 \\
\hline & Other & 5 & 1.5 & 4 & 1.2 \\
\hline & Total & 345 & 100 & 345 & 100 \\
\hline \multirow[t]{5}{*}{ Religion } & Protestant & 29 & 8.4 & 22 & 6.4 \\
\hline & Orthodox & 100 & 29 & 111 & 32.2 \\
\hline & Muslim & 216 & 62.6 & 211 & 61.2 \\
\hline & Other & 0 & 0 & 1 & 0.3 \\
\hline & Total & 345 & 100 & 345 & 100 \\
\hline \multirow[t]{4}{*}{ Educational level } & Unable to read \& write & 147 & 42.6 & 94 & 27.2 \\
\hline & $\begin{array}{c}\text { able to read \& } \\
\text { write but no formal } \\
\text { education }\end{array}$ & 75 & 21.7 & 73 & 21.2 \\
\hline & Formal education & 123 & 35.7 & 178 & 51.6 \\
\hline & Total & 345 & 100 & 345 & 100 \\
\hline \multirow[t]{5}{*}{ Occupation } & Farmer & 263 & 76.2 & 261 & 75.7 \\
\hline & Merchant & 28 & 8.1 & 34 & 9.9 \\
\hline & Gov. employee & 14 & 4.1 & 29 & 8.4 \\
\hline & Other & 40 & 11.6 & 21 & 6.1 \\
\hline & Total & 345 & 100 & 345 & 100 \\
\hline
\end{tabular}

Women Age, Education and Family Size Versus Their Current Contraceptive Use

When adjusted women education and family size, those mothers in age group 25 to 29 , being able to read and write, family size greater than 5 were more likely to use family planning currently, $\mathrm{AOR}$ and $\mathrm{CI}=(\mathrm{AOR}=2.6,95 \% \mathrm{CI}=1.14,5.99),(\mathrm{AOR}=2.0(\mathrm{CI}, 1.1,3.7)$, $(\mathrm{AOR}=1.895 \% \mathrm{CI} 1.03,3.14)$ respectively (Table2). 
Table 2: Women Age, Education and Family Size Versus their Current Contraceptive Use, Couples of Five Administrative Village Dodota District, South-East Ethiopia 2016.

\begin{tabular}{|c|c|c|c|c|}
\hline Variable & Yes & No & Curd OR & AOR \\
\hline Age & No (\%) & No (\%) & $95 \% \mathrm{CI}$ & $95 \% \mathrm{CI}$ \\
\hline $16-19$ & $20(9.4)$ & $84(17.6)$ & 1 & 1 \\
\hline $20-24$ & $23(10.8)$ & $73(15.3)$ & $1.8(0.8,3.6)$ & $1.5(0.7,3.1)$ \\
\hline $25-29$ & $47(22)$ & $69(14.4)$ & $3.1(1.3,6.9)^{*}$ & $2.6(1.1,5.9)^{*}$ \\
\hline $30-34$ & $79(37.2)$ & $68(14.2)$ & $1.1(0.5,2.4)$ & $1.0(0.3,2.3)$ \\
\hline $35-39$ & $22(10.3)$ & $64(13.4)$ & $1.3(1.2,1.5)^{*}$ & $1.0(0.1,1.1)$ \\
\hline $40-45$ & $16(7.5)$ & $42(8.8)$ & $1.4(1 \cdot 3,1.6)^{*}$ & $1.1(0.8,1.2)$ \\
\hline $46+$ & $5(2.3)$ & $27(5.6)$ & $1.3(1 \cdot 2,1.3)^{*}$ & $1.0(0.9,1.2)$ \\
\hline \multicolumn{5}{|c|}{ Education Level } \\
\hline Unable to read \& write & $22(21.6)$ & $63(45.6)$ & 1 & 1 \\
\hline Able to read \& write & $33(32.3)$ & $51(36.9)$ & $2.1(1.2,3.8)^{*}$ & $2.0(1.1,3.7)^{* *}$ \\
\hline Formal education & $47(46.1)$ & $24(17.4)$ & $1.6(0.8,3.3)$ & $1.5(0.7,3.2)$ \\
\hline \multicolumn{5}{|c|}{ Family Size } \\
\hline$<5 y r s$ & $213(61.6)$ & $133(38.4)$ & 1 & 1 \\
\hline$>5$ & $127(36.9)$ & $217(63.1)$ & $1.9(1.1,3.4)^{*}$ & $1.8(1.0,3.1)^{* *}$ \\
\hline
\end{tabular}

Table 3: Husbands Age, Education and their status regarding family planning information versus current contraceptive use by wives couples of Dodota district south east Ethiopia, 2016.

\begin{tabular}{|c|c|c|c|c|}
\hline Variable & Yes & No & Curd OR & AOR \\
\hline Age & No (\%) & No $(\%)$ & $95 \% \mathrm{CI}$ & $95 \% \mathrm{CI}$ \\
\hline $16-19$ & $51(19.2)$ & 11(13.7) & 1 & 1 \\
\hline $20-24$ & $59(22.3)$ & $9(11.2)$ & $2.2(1.0,4.6)^{*}$ & $2.1(1.0,4.4)^{* *}$ \\
\hline $25-29$ & $56(21.1)$ & $10(12.5)$ & $1.2(1.0,1.4)^{*}$ & $1.0(-0.9,0.3)$ \\
\hline $30-34$ & $47(17.7)$ & $18(22.5)$ & $2.0(0.9,4.2)$ & $2.3(1.1,5.0)^{* *}$ \\
\hline $35-39$ & $24(7.9)$ & $14(17.5)$ & $2.2(1.1,2.5)^{*}$ & $2.1(1.3,3.0)^{* *}$ \\
\hline $40-45$ & $21(9.1)$ & $12(15)$ & $1.3(1.1,1.8)^{*}$ & $3.0(-2.4,1.5)$ \\
\hline $46+$ & $7(2.6)$ & $6(7.5)$ & $1.2(1.1,1.4)^{*}$ & $1.0(-0.7,0.2)$ \\
\hline \multicolumn{5}{|c|}{ Education Level } \\
\hline Unable to read \& write & $42(24.8)$ & $69(39.2)$ & 1 & 1 \\
\hline $\begin{array}{l}\text { Able to read \& write but no } \\
\text { formal education }\end{array}$ & $31(18.3)$ & $57(32.4)$ & $1.6(0.7,3.3)$ & $1.5(0.6,3.3)$ \\
\hline Formal education & $96(56.8)$ & $50(28.4)$ & $1.9(0.9,4.0)$ & $1.8(0.8,3.8)$ \\
\hline \multicolumn{5}{|c|}{ Had Information on Family planning } \\
\hline No & $58(19.3)$ & $26(59)$ & 1 & 1 \\
\hline Yes & $243(80.7)$ & $18(41)$ & $2.4(1.1,4.9)^{*}$ & $2.5(1.1,4.7)^{* *}$ \\
\hline
\end{tabular}

\section{Husbands' Age, Education and Their Status of Family Planning Information Versus Current Contraceptive Use by Wives in Dodota, Arsi, Ethiopia}

Women in age group of 20-24. 30-34, 35-39 were more likely to use family planning currently and those who have family planning information also more likely to use currently AOR $=2.1$ (CI 1.0, 4.4), $\mathrm{AOR}=2.3(\mathrm{CI}, 1.1,5.0), \mathrm{AOR}=2.1(\mathrm{CI}, 1.3,3.0), \mathrm{AOR}=2.5(\mathrm{CI}, 1.1,4.7)$ respectively(Table3).

Children Ever Born and Alive and Ideal Interval Wanted Versus Contraceptive Current Use by Women in Dodota

\section{District, South Eastern Ethiopia, 2016}

The rate of current contraceptive use is significantly higher for those women with at least five children ever born $(\mathrm{AOR}=2.2$, 95\% CI=1.2, 3.9) (Table 4).

\section{Discussion}

This community-based study used information from both husband and wife accessed factors that were assumed to be affecting family planning service utilization by women. Accordingly, women who currently use contraceptive method tend to be relatively older, educated, with large family, and those who perceive their husbands' 
approval of contraception use. Those husbands who were older than 30 years, have information about family planning, communicate on family planning issues and initiate family planning use by their wives. Consistent to the finding by most demographic and health surveys in Africa, this study also found that more than $88 \%$ of both men and women have knowledge about family planning and nearly $76 \%$ of them approve the use of Family Planning [7,11].

Table 4: Children Ever Born and Alive and Ideal Interval Wanted Versus Contraceptive Current Use by Women, Couples of 5 Administrative Village of Dodota District, South Eastern Ethiopia, 2016.

\begin{tabular}{|c|c|c|c|c|c|}
\hline \multirow[b]{2}{*}{ Variable } & \multicolumn{4}{|c|}{ Contraceptive current use by women } & \multirow[b]{2}{*}{ A OR 95\%CI } \\
\hline & Yes (\%) & No (\%) & Total & Crud OR 95\%CI & \\
\hline \multicolumn{6}{|c|}{ Child Ever Born } \\
\hline$<5$ & $79(23)$ & $72(21)$ & $151(43.9)$ & 1 & 1 \\
\hline$>5$ & $118(34)$ & $76(22)$ & $194(56)$ & $1.9(1.1,3.6)^{* *}$ & $2.2(1.2,3.9)^{* *}$ \\
\hline \multicolumn{6}{|c|}{ Number of Children Alive } \\
\hline$<5$ & $105(47.3)$ & $57(46.3)$ & $162(46.9)$ & 1 & 1 \\
\hline$>5$ & $117(52.7)$ & $66(53.7)$ & 183(53.1) & $2.2(1.2,3.9)^{*}$ & $2.6(0.7,9.8)$ \\
\hline \multicolumn{6}{|c|}{ Interval Wanted for Child Spacing } \\
\hline$<3$ years & $47(39.2)$ & $108(48)$ & $155(44.9)$ & 1 & 1 \\
\hline$>\neg 3$ years & $73(60.8)$ & $117(52)$ & $190(55.1)$ & $1.2(0.6,2.2)$ & $1.2(0.6,2.2)$ \\
\hline
\end{tabular}

The mean age difference between husband and wife was 5.83 years. The minimum age for men at which they got their first birth was 17 years, for women it was 16 years. The mean age at which respondents got their first birth was 25.10 for men and 20.44 years for women respectively. The mean age difference of husband and wife at their first birth was 4.66 years. The mean number of children ever born to women was 3.79. Although the mean number of children ever born to men is greater than that for women, AOR $(2.295 \% \mathrm{CI}=1.2,3.9)$ the mean ideal number of children desired by men was 6.13 and by women were 5.8 [12]. This might be due to the fact that burden and associated risks more concern women which make men involvement in family planning program paramount Importance. Nearly $169(46.4 \%)$ reported family size of less than six. The average family size reported was six which was greater than average household in Ethiopia 2011 [7].

About $124(35.9 \%)$ of women and $88(25.5 \%)$ of men reported current use of contraceptive method. These show that women current user $10 \%$ higher than male users. But 34(9.9\%) of women and 23(6.7) of men reported discontinuation due to fear of side effects.Men were asked about current contraceptive use by their wives. $88(25.5 \%)$ of men reported that their wives were using contraceptive methods during the study period. This is comparable with the wives' report of 124(35.9\%) current contraceptive use even though ten percent of women use without knowledge of their husbands. This might have implication of less involvement of men in fertility control of their wives or might be the women afraid of disclosing their fertility control practices. This needs further exploration.The proportion of women who reported current contraceptive use was the highest in age group 30-34, where $79(37.2 \%)$ were current users.

The least proportion of current use of family planning method was reported by age group 46 and above. When adjusted for women education and family size, those mothers in age group 25 to 29 had show nagreater likely hood to use contraception than mothers of other age $(\mathrm{AOR}=2.695 \%=1.14,5.99)[13]$. The contraceptive prevalence rate for women is lower compared to the regional (Oromia) report, 35.9\%, and40.1\%, respectively [7] despite different parts of the country contraceptive prevalence rate ranging $3 \%$ to $64 \%$ at Somalia and Addis Ababa respectively in which case the higher prevalence could be attributable to better knowledge and positive attitude towards the use and the higher proportion of couples who had discussion on family planning issues $[11,14]$. Only half of the couples reported discussion about family planning issues and about $76 \%$ of them (both male \& female) know contraceptive method and approve family planning method utilization. In agreement with the study Tigray, the men contraceptive prevalence rate is very low [15].

The proportion of women who reported current contraceptive use was highest in age group $30-34$, where $37.2 \%$ were contraceptive users. The high prevalence in this age group is consistent with the study done at Gondar and the Ethiopian Demographic health survey $2014[7,15]$. The least proportion of current use of family planning method was reported by age group $46+$. The possible explanation is that most women strive to have the number of children they want during their younger age, and at around 30 they might have already achieved their desired number of children [5].Study in Addis Ababa, area has shown that women with young partners are at relatively conducive environment to use family planning methods compared to those with partners of older age [16]. In contrast, this study has shown that women with husbands who are older than 30 years tend to use contraception more than with those husbands who are younger. According to this study; most men want to have children which may not give enough time for the wife to initiate contraception before men's age of 30. This might be due to the difference in socio-demographic between the area of current study and Addis Ababa the capital city.Keeping the earlier findings $[17,15]$, educated women tend to use contraception more than those women with no formal education. 
The bivariate analysis result showed that those with formal education had higher likelihood of using contraceptive than those with low level of education; which may be attributed to less number of individuals in the category to give significant relationship. If we assume that contraceptive use would lead to lower fertility, this finding is in contrary to the findings elsewhere which relates fertility reduction with higher level of education and which associates low level of education to result in higher fertility compared to no education [18]. On other hand, although current contraceptive use by women increases as educational level attained by men increase. Family size of five and above and at least three live children are positively associated with current contraceptive use by women $(\mathrm{AOR}=3.9,95 \% \mathrm{CI} 1.9,7.8)$. The issue of number of children alive may also be related to child survival. Although the child survival effect was not sought in this study, the effect can be indirectly seen by the number of children alive. Those with larger number of children would use family planning method more than those with lesser number.

However, the parents' perception of not losing a child (improving child survival) should be a major focus with this regard.With growing attention of involving men in family planning and reproductive health, the main assumption is that men would be good advocates for promoting family planning services $[10,11]$. Supporting this assumption, those women who were informed by their husbands to use contraception are more likely to report current use of contraception than those who were not initiated by their husbands. Similarly, current contraceptive use is positively and strongly related to men's knowledge of family planning. Congruently to this couple's discussion about family planning has long been found out as paving way for family planning utilization [19].The perception of approval of husbands by women on use of contraceptive was one of the predictor of contraceptive use among the study subjects which is very essential area of intervention by creating awareness of husbands on this issue. The difference observed between men and women determinants could be explained by the distinct nature of economic responsibilities and interest to childbearing and other economic issues as clearly explained by the transaction theory of fertility decision making $[19,20]$. Transaction theory which places the locus of reproductive health decision making at the individual rather than at the household level. It assumes, although husband and wife live in the same household, they have distinct economic responsibilities and interest regarding to childrearing and other economic issues. The husband encourages the wife to use FP, he can participate in FP utilization directly or indirectly consistent with other study [18].

\section{Conclusion}

In married couples, both men and women factor affect contraceptive utilization by the women. of those factors: information of family planning methods by men, men as advocate for contraceptive use, family size, women education, are all found to be positive determinants for family planning use by women. Both husband and wife age, child ever born and alive for the couples, are important predictive variables for the wives' use of contraception.
Most men have information about family planning, some encourage their wives to use family planning method and most of them are in need of family planning methods in future. The majority of men share decision making on family issues, including family planning with their wives.Unlike the female contraceptive options, the men contraceptive options including condom is not widely known by the community. The inject able is giving way for the oral contraceptive as the leading family planning method used and preferred by majority of women.When both husband and wife have information on family planning the probability of the women to use the methods is higher than when only either of the couples is informed. This finding signals that programmers and implementers shall stress on men participation of family planning methods utilization.

\section{Recommendations}

a. Couples should be informed on the available men contraceptive option; it is known that the men contraceptive options are limited compared to that of women. But still the existing men contraceptive options are not well known by majority of the community.

b. Men should be encouraged to use the existing men contraceptives; the majority of men are willing to use contraception. The lack of wide range of men contraceptive option shouldn't be a reason for not promoting the men contraception.

c. Men should be used as agent for family planning service promotion; since when husbands inform their wives to use contraception the wife tend to use more.

d. Appropriate counseling on possible side effects before start of family planning method use may help the user to cope with some expected side effects.

\section{Acknowledgement}

The authors of this original paper acknowledge Arsi University Graduate Study Directorate, Health Science College Post graduate coordinators and Public Health Department and Dodota District Health Office as well the participants of this study for their contribution. The authors also extend recognize the contribution of the data collectors for the commitment they had during data collection. We also extend our acknowledgement to our families for their encouragement throughout the processes of the research work and publication of the manuscript.

\section{References}

1. UNFPA (2016) The world population estimation: The world population report, Geneva, Switzerland.

2. Vouking MZ, Evina CD, Tadenfok CN (2014) Male involvement in family planning decision making in sub Saharan Africa what the evidence suggests, Pan African medical journal 19: 349.

3. Central Statistics Authority (1999) Population and Housing Census of Ethiopia, Result at Country Level, Analytical Report, CSA, Addis Ababa, Ethiopia.

4. Population Reference Bureau (2002) Women of Our World. Washington, DC. PRB, USA. 
5. Bekele AT, Mccabe C (2006) Awareness and determinants of family planning practice in Jimma, Ethiopia International Nursing Review 53: 269-276.

6. Mihretie K, Amanuel A, Molla G (2014) Level of male involvement and associated factors in family planning service utilization among married men in Debmarkos town North West Ethiopia 14: 33.

7. Central Statistical Authority, ORC. MACRO (2011) Ethiopia Demographic and Health Survey. EDHS report, Addis Ababa, Ethiopia

8. Paulina MA (2001) Socio-cultural Factors Affecting Fertility in SubSaharan Africa. Workshop on Prospects for Fertility Decline in High Fertility Countries, UN/POP/PFD report.

9. Ademola A Philomina O, Elizabeth E, Philomena Omoregie (2014) Male involvement in family planning and the way foreword Nigeria. International Journal of Population Research pp. 9.

10. (2015) The Bill and Melinda Gates Institution for Population Reproductive Health at the Johns Hopkins Bloomberg School of Public Health. Makerere University's School of Public Health, and the Implementing Best Practices Initiative Assessment of the role of men in family planning utilization at Edaga Hamuse Town Tigray, North Ethiopia. American Journal of Nursing Sciences 4(4): 174-181.

11. UNFPA (1995) Male Involvement in Reproductive Health, Including Family planning and Sexual Health. Technical Report. No.28, UNFPA, New York.

12. Tilahun, Gily Coene, Marleen Temmerman, Olivier Degomme (2015) Couples based family planning education changes in male involvement and contraceptive use among married couples in Jimma Zone Ethiopia. BMC Public Health 15: 682.

13. Mohammad Mostufa Kamal, Shahidul Islam Md, Muhammad Shafiul Alam, Enamol Hassan ABM (2013) Determinants of male involvement in family planning and reproductive health in Bangladesh. American Journal of Human Ecology 2(2): 83-93.

14. Ethiopian Central Statistical Agency (2014) Ethiopian mini Demographic and Health Survey, EDHS Report, Addis Ababa, Ethiopia.

15. Gebre kidan M (2002) The role of men in fertility and family planning programme in Tigray Region, Ethiop. J Health Dev (16): 247-255.

16. Yohannes $\mathrm{T}$ (2004) The role of men in family planning in a rural community of Bodji District, Western Ethiopia.

17. Annable S (2009) International conference on family planning research and best practice Kampala Uganda November p. 15-18.

18. Kora A (1997) Community Based Family Planning Services. A Performance Assessments of Jimma Family Planning CBD project Ethiop. J Health Dev 11(1): 17.

19. Yigzaw K (2000) Contraceptive prevalence and factors associated with usage of contraceptives around Gondar Town, Ethiop. J Health Dev 14(3): 327-334.

20. Kaba M (2000) Fertility regulations among women in rural communities around Jimma, Western Ethiopia, Ethiop. J Health Dev 14(2): 117-126.

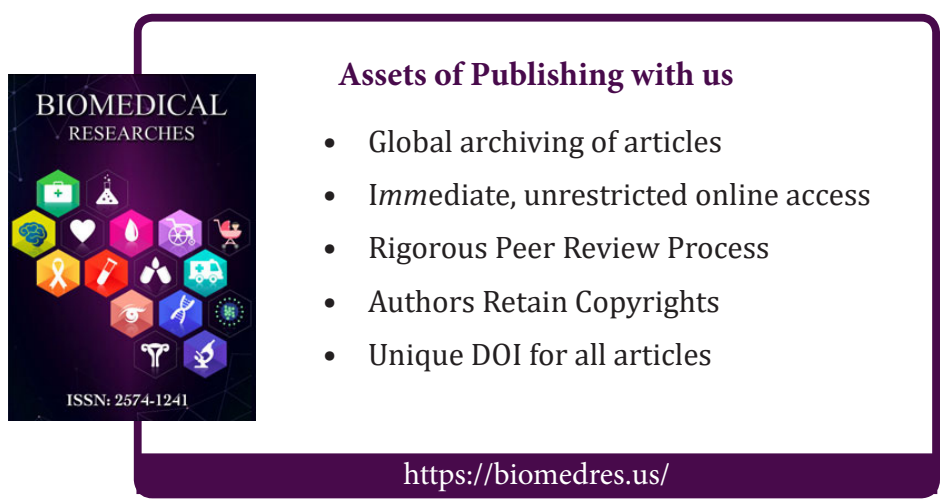

